\title{
PROPOSTAS DE PRODUÇÃO DE TEXTOS EM UM LIVRO DIDÁTICO: ANÁLISE DAS ORIENTAÇÕES DESTINADAS AOS ALUNOS
}

\author{
${ }^{1}$ Fabiana Goes da Silva Agostinho, Odair Benedito Francisco \\ 'Universidade Estadual Paulista - UNESP. ${ }^{2}$ Universidade do Oeste Paulista - UNOESTE, E-mail: \\ fabigoessc@hotmail.com, odair272@yahoo.com.br.
}

\section{RESUMO}

Sob a ótica da concepção da linguagem como forma de interação, sabemos da necessidade de trabalhar propostas de produção de texto de forma contextualizada, considerando os pressupostos necessários para um bom planejamento e para a elaboração de texto, fornecendo, portanto, requisitos que se atentem às condições para a produção textual. Nesse sentido, o presente estudo teve como objetivo analisar as propostas de produção textual no livro didático Porta Aberta (edição renovada), do quarto ano do Ensino Fundamental I, aprovado pelo Programa Nacional do Livro Didático (PNLD), visando constatar se ele segue essa concepção e se contém propostas interessantes e efetivas aos alunos. A metodologia teve base em uma análise documental, observando se foram considerados os aspectos referentes à tipologia, às condições de produção e à contribuição para a construção da textualidade. Como resultados, destacamos que ainda há planejamentos inadequados presentes nos livros didáticos, faltando os requisitos que facilitariam a produção do aluno, tais quais, a tipologia, condições de produção, contribuições para elaboração temática, planejamento, revisão e reelaboração de texto. Em concomitância, o uso destes requisitos daria, ao mesmo tempo, sentido à ação de escrever, pois dessa forma aproximar-se-ia do uso real da língua. Concluímos que, apesar dos avanços na elaboração de propostas de produção textual oferecidas pelos livros didáticos no ensino Fundamental dos anos iniciais, como por exemplo, a ação de possibilitar condições para a construção do texto, o foco ainda é concentrado na estrutura do texto, no entendimento do gênero, e não especificamente em sua função social.

Palavras-chave: Gêneros Textuais, Livro Didático, Produção de Texto.

\section{PROPOSALS OF TEXT'S PRODUCTION IN A BOOK: ANALYSIS OF THE GUIDELINES INTENDED TO LEARNERS}

\begin{abstract}
Under the perspective of language conception as a way of interaction, we have known the need to create proposals of text production in a contextualized way, considering the assumptions needed for good planning and text elaboration, providing thus, requirements that meet the conditions for textual production. In this sense, this study aimed to analyze the textual production proposals in the textbook Porta Aberta (renewed edition), of the fourth year of elementary school I, approved by the National Textbook Program, to see if it follows this conception and, if it contains interesting and effective proposals to students. The methodology was based on a documentary analysis, observing if were considered the aspects related to the typology, the conditions of production and the contribution to textuality construction. As results, we emphasize that there is inappropriate planning present in textbooks, missing the requirements that would facilitate student's production, such as, the typology, production conditions, contributions to thematic elaboration, planning, reviewing and reworking text. Concurrently, the use of these requirements would give sense, at the same time, to the act of writing, since in this way it would be approached to the real use of language. We have concluded that, despite advances in drawing up the proposals of textual production offered by textbooks in the early years of elementary school, as for example, the action of offering conditions for the text construction, the focus is still on text structure, in the understanding of genre, and not specifically in its social function.
\end{abstract}

Keywords: Textual Genre, Textbook, Text Production. 


\section{INTRODUÇÃO}

“[...] o fenômeno do analfabetismo funcional é em particular intrigante porque nos obriga a admitir a realidade aparentemente

contraditória de indivíduos que, mesmo tendo passado pelo processo formal de escolaridade, são incapazes de ler e escrever. Apesar da dificuldade conceitual em definir a funcionalidade da escrita em uma sociedade marcada pela explosão tecnológica e informativa, o descompasso entre as exigências do nosso mundo letrado e a resistência da escola ultrapassada parece indiscutível" (FERREIRO, 2001; 2002 apud COLELLO, 2012, p.141)

À luz dos argumentos expostos por Ferreiro (2001), há a indagação quanto ao processo de ensino e aprendizagem no que diz respeito à produção textual nas escolas de Ensino Fundamental I, especialmente nos quartos e quintos anos, nos quais há ou deveria haver uma maior autonomia na escrita dos alunos.

Primeiramente, o questionamento chegou como forma de acusação, sendo o aluno apontado como o foco do problema de aprendizagem em relação à produção de textos, tendo em vista que o discurso do desinteresse dos alunos é constante, frente às situações vividas em sala de aula. Esta realidade pôde ser vista principalmente nos momentos de aprendizagem e, no desenvolvimento de atividades com textos, os quais resultaram na não participação dessas crianças. Nessa perspectiva de acusação, estes são alunos que não leem, pois vivem em um mundo de alternativas mais rápidas, no que diz respeito à utilização das ferramentas tecnológicas e, preferem as produções e leituras curtas e simplistas, como as mensagens enviadas por meio de aplicativos de celular ou ainda, pelas redes sociais.

Esse pensamento acaba sendo um tanto quanto contraditório, haja vista que as crianças, perante o acesso a estas informações rápidas propiciadas pelas ferramentas produtivas de texto, estão em contato com a leitura e a escrita, mesmo que não seja da maneira mais diversificada e aprofundada possível. Destarte, não podemos desconsiderar as vivências e o contato desses alunos com a leitura e a escrita, seja da forma que for, pois é importante reconhecer que a interação acontece de alguma forma, ainda que o foco da utilização da língua tome outros caminhos e não idealize a forma culta, dando lugar a outras variantes. São essas marcas que mostram como uma língua mudou e mostram também a ligação que há entre as transformações sociais e as transformações linguísticas.

É preciso compreender as transformações sociais percebidas no uso da língua e encontrar novas maneiras de trabalhar a partir delas, respeitando as novas formas de comunicação e extraindo-lhes possibilidades de aprofundamento no estudo da língua.

Os Parâmetros Curriculares Nacionais de Língua Portuguesa- PCNLP (BRASIL,2001) tratam sobre a mudança do perfil social e cultural dos alunos, além de discorrer sobre a finalidade da educação para responder às novas exigências sociais, às quais estamos diante e, que resultariam em transformações educacionais. Podemos então afirmar que se trata de desinteresse dos alunos? Quanto a isso, Colello (2012) afirma que:

A atividade mecânica e as
práticas
descontextualizadas e
pouco significativas, ao
invés de promover a
reflexão crítica ou a
criatividade são uma
promoção reducionista do
conhecimento, que acaba
por fazer surgir uma
reação rebelde de
descomprometimento
(COLELLO, 2012, p. 154).

Frente a tais apontamentos, os questionamentos se atenuam e buscam novos caminhos, considerando-se a experiência de um dos autores no 40 e 5o ano do Ensino Fundamental I, que já se deparou com o uso dos mesmos discursos e resolveu fazer, em um determinado momento, uma autoavaliação de sua prática pedagógica diante do uso de instrumentos de produção textual em sala de aula. Foi possível notar a prática da produção textual de maneira descontextualizada, sem a 
apresentação de objetivos, sem explicitar aos alunos quais seriam os leitores de suas histórias, sem definir meios de apresentar seus trabalhos, ou mesmo sem apresentar uma finalidade, ou seja, em uma ação de escrever por escrever, sem uma motivação real que os fizessem perceber para que eles escreviam.

Colello (2012) ressalta que a produção de textos está fortemente influenciada pela identidade de quem escreve, não apenas relacionada aos aspectos cognitivos, mas especialmente pelo contexto sociocultural que envolve dimensões afetivas, linguísticas, sociais e pedagógicas. As vivências e os conhecimentos dos alunos devem ser considerados como componentes essenciais no desenvolvimento da produção textual, para que possam ser ampliados. Em vista disso, é preciso considerar o contexto de produção da escrita e as condições efetivas para que a produção possa ser desenvolvida. Neste sentido, Geraldi (2003 apud COLELLO, 2012) afirma que:

$$
\begin{aligned}
& \text { a produção de texto } \\
& \text { requer que se tenha o que } \\
& \text { dizer, para que dizer, a } \\
& \text { quem dizer; que se possa } \\
& \text { assumir a condição de } \\
& \text { efetivo locutor, e, } \\
& \text { finalmente, que se tenham } \\
& \text { estratégias para atender a } \\
& \text { todos esses requisitos [...] } \\
& \text { valorizar o foco social do } \\
& \text { escrever [...] as } \\
& \text { possibilidades } \\
& \text { interlocutivas que dão } \\
& \text { sentido à escrita (GERALDI, } \\
& 2003 \text { apud COLELLO, 2012, } \\
& \text { p.150). }
\end{aligned}
$$

Sistematizando o pensamento de Geraldi (2003), faz-se necessário então a apresentação de um tema (o que escrever), a escolha de um gênero textual para indicar as funções sociais do mesmo (para quê) e a existência de um interlocutor (a quem), devendose também possibilitar o embasamento por meio da disponibilização de outros textos (como escrever). Dessa maneira, há uma motivação para o ato da escrita.

Diante disso, este trabalho tem como objetivo analisar as propostas de produção de textos oferecidas em um livro didático, destinado ao uso do 4ㅇ ano do Ensino Fundamental I, aprovado pelo PNDL (Programa Nacional de Livro Didático), para verificar se há ou não adequação, em conformidade com as recomendações dos PCNLP, os quais adotam a concepção de linguagem enquanto forma de interação.

\section{METODOLOGIA}

Segundo Geraldi (2006, p.41), na concepção de linguagem como forma de interação, "mais do que possibilitar uma transmissão de informações de um emissor a um receptor, a linguagem é vista como um lugar de interação".

Nesse contexto foi realizada uma análise documental referente ao livro didático "Porta Aberta", do 40 ano do Ensino Fundamental, no que tange às suas propostas de produção de texto. A coleção em questão foi utilizada pela rede municipal de uma cidade de médio porte do oeste paulista, entre os anos letivos de 2013 a 2015. Ressalta-se ainda que o livro analisado faz parte da edição renovada da coleção, aprovada pelo PNLD.

A análise das propostas levou em conta as seguintes categorias de análise, evidenciadas por Reinaldo e Santana (2005, p.105):

- Tipologia (diversidade de gêneros discursivos e tipos de textos);

- Condições de produção (indicação de objetivo para a produção do texto, de destinatário, de circulação, do veículo ou suporte textual);

- Contribuição para construção da textualidade pelo aluno (contribuição para a elaboração temática, proposta de planejamento, de revisão e de reelaboração de textos).

Quanto à análise documental como método de investigação, Lüdke e André (1986, p. 38), afirmam que trata-se de uma "técnica valiosa de abordagem de dados qualitativos, seja complementando as informações obtidas por outras técnicas, seja desvelando aspectos novos de um tema ou problema", uma vez que os documentos, no caso específico desta pesquisa, o livro didático,

[...] constituem uma fonte poderosa de onde podem ser retiradas evidências que fundamentem 
afirmações e declarações do pesquisador. Representam ainda uma fonte "natural" de informação, não sendo apenas uma fonte de informação

contextualizada, mas surge num determinado contexto e fornecem informações sobre esse mesmo contexto (LÜDKE e ANDRÉ, 1986, p. 39).

Por outro lado, a pesquisa bibliográfica de cunho qualitativo priorizou os escritos de autores renomados que tratam sobre a produção textual na escola, encontrados em livros, artigos originais e de revisão, os quais abordam o tema em evidência, assim como, materiais encontrados em revistas e em sites educacionais da internet.

\section{ANÁLISE E DISCUSSÃO DOS RESULTADOS}

No cotidiano escolar, o que realmente acontece é a utilização da produção de textos como um fim e não como um meio de participação social cuja finalidade é inserir o estudante nas práticas sociais de escrita presentes no meio sociocultural no qual ele se encontra.

Colello (2012) destaca que a produção escrita dos nossos alunos, em uma concepção ingênua, torna-se apenas um reflexo do conhecimento sobre o sistema linguístico, sendo vista como um produto, o que justificaria um ensino focalizado na gramática e na ortografia. Já para Geraldi (2006, p. 65), "a produção de textos na escola foge totalmente do sentido usual da língua; os alunos escrevem para o professor (único leitor). A situação de emprego da língua é, pois, artificial".

Outrossim, encontramos uma realidade na qual o aluno não encontra as orientações necessárias para produzir seus textos. Para Britto (2006, p. 118) "a língua é meio privilegiado de interação entre os homens. Em todas as circunstâncias em que se fala ou se escreve há um interlocutor". No entanto, nas produções propostas na escola há a ausência de interação, o que pode representar problemas na construção do texto por parte do aluno, gerando dificuldades na obtenção de coesão do texto. Segundo o autor, podem surgir os seguintes problemas:

- Na produção do texto, o aluno opta pela utilização de palavras que não usaria normalmente, pois acredita que isso seja o esperado pelo professor, a quem frequentemente se escreve. Assim sendo, escreve o que acredita que o professor gostará de ler, baseado na ideia da visão de língua do professor (BRITTO, 2006).

Em relação a isso, Possenti (1981 apud BRITTO, 2006) cita que "dependendo da imagem que o locutor faz do interlocutor no momento da produção do discurso, que utiliza um ou outro mecanismo coesivo [...] indiretamente é a imagem do interlocutor que comanda a decisão".

Outro problema relevado por Britto (2006), diz respeito à estratégia de preenchimento:

- Na tentativa de escrever em uma linguagem que considera culta, 0 estudante emprega recursos que não sabe realmente utilizar, além de fazer uso de frases de efeito e ter a necessidade de escrever bastante, enchendo a folha para mostrar que sabe o conteúdo ou, que está dizendo algo, quando efetivamente não está. Neste sentido, mais uma vez podem ser vistos os problemas de coesão (BRITTO, 2006).

O aluno acredita que não adianta escrever em conformidade com as suas possibilidades de escrita, pois crê que isso não será o suficiente para agradar o seu leitor, no caso o professor, seu avaliador. A escrita, então, não é espontânea, pois sabe-se que a avaliação será feita com base na escrita, na escolha lexical e, no uso de recursos coesivos. Nessas condições, o estudante sabe que durante a leitura do professor, o foco não será a mensagem escrita ou a criatividade ao escrever, mas sim a estrutura do texto, avaliando tanto as estruturas gramaticais, quanto a relação com as condições estabelecidas para a produção de determinado gênero textual.

À vista disso, vem à tona uma insegurança no produtor do texto, no caso, o aluno, que por essa razão acredita ser incapaz de escrever, e vê a folha em branco apenas como algo a ser preenchido para o professor. Um exemplo, neste sentido, é a frequente pergunta feita em sala de aula, em ocasião de uma proposta de produção de texto, ou seja, "quantas linhas precisa escrever?", como se fosse possível delimitar 
um espaço para que uma mensagem seja dita apropriadamente.

É possível perceber que muitos professores ainda não têm clareza quanto à sua concepção de linguagem, necessitando de um instrumento de apoio na elaboração de propostas de produção textual. Muitas vezes, mais do que apoio, procuram mesmo um guia para a orientação de atividades nas aulas de Língua Portuguesa, encontrando-o nos livros didáticos adotados.

É certo que, ainda há grandes questionamentos acerca da utilização desse recurso em sala de aula, enquanto único instrumento adotado pelo professor, tendo em vista a orientação existente para a busca de outros recursos, no sentido de ampliar as possibilidades experienciadas nas aulas e, não se ater ao uso exclusivo do livro didático.

Ao mesmo tempo, sabemos que muitas vezes este é o único recurso disponível aos professores, os quais, talvez por insegurança, ou por não ter clareza sobre suas concepções, conforme mencionado anteriormente, optam por essa exclusividade.

Por conseguinte, "numa reação em cadeia, os manuais didáticos transitam pelas teorias linguísticas, tentando atender aos critérios estabelecidos pelo PNLD e às diretrizes dos PCN" (DIONÍSIO, 2002, p. 82).

Ainda neste sentido, segundo Volmer e Ramos (2009), a definição de livro didático não é recente no Brasil, tendo início na década de 30 , com o decreto-lei no 1006, de 30 de dezembro de 1938. O mesmo decreto tem como objetivo a regulamentação de uma política nacional do livro didático e, perpassa por várias Comissões e Institutos, até o decreto-lei no 91.542, de 1985, que, para garantir uma política de regulamentação mais eficiente, cria o PNLD.

No processo de escolha dos livros, há várias fases, incluindo a análise dos materiais previamente aceitos. Os livros didáticos de Língua Portuguesa são avaliados segundo a concepção interacionista da linguagem, obedecendo alguns aspectos, destacados por Marcuschi (2007): texto como unidade básica de ensino, propostas contextualizadas para as produções linguísticas, diversidade de gêneros, reflexão sobre a língua e seus usos, sem que a gramática seja o ponto principal e; variedades do uso da língua.
Todas as unidades do livro didático em questão, totalizando nove unidades de estudo, trazem em algum momento a proposta para a produção de textos, sendo um tópico intitulado "Produção" e, quatro outros apresentados sob a terminologia "Oficina". As unidades foram contempladas em sua totalidade para a observação dos gêneros trabalhados, com o propósito de que fosse percebida a relação de gênero trabalhada durante a unidade e ainda, o gênero exigido na proposta de produção de texto da mesma.

A análise das propostas de texto, além das categorias elencadas na metodologia, considera também que "a orientação para a produção de textos não deve se dar como um procedimento único e global, aplicável a qualquer texto, mas um conjunto de aprendizagens específicas para cada gênero" (REINALDO; SANTANA, 2005, p.103). Dessa forma, a elaboração das propostas de produção textual deve considerar o gênero a ser desenvolvido, tendo em vista que cada um traz exigências específicas, que não podem ser ignoradas.

Nas orientações destinadas aos professores, localizadas no anexo do livro didático analisado, especificamente entre as páginas 285 a 287, Carpadena e Bragança (2014) apresentam como objetivo da produção de textos, em concordância com os Parâmetros Curriculares Nacionais de Língua Portuguesa, a necessidade de "criar situações em que a escrita tenha um objetivo (para que) e um destinatário definido (para quem) e, auxiliar o aluno no sentido de adequar a linguagem e a forma a serem utilizados (como escrever)" (CARPADENA; BRAGANÇA, 2014, p. 285).

Além disso, as autoras também retratam a importância de trabalhar a produção em etapas, incluindo o planejamento (delimitação do tema e objetivos), elaboração (a escrita propriamente dita, explorando as especificidades do gênero escolhido), revisão (autoavaliação com ênfase na organização e nos aspectos da escrita) e refacção (reelaboração do texto).

Mediante a leitura detalhada, é possível constatar a preocupação das autoras quanto aos aspectos elencados, mas, nem todos são trabalhados em cada uma das unidades do livro didático de maneira efetiva, já que a etapa de refacção, na maioria das unidades, nada mais é do que passar o texto a limpo. Algumas propostas ampliam essa questão, orientando a troca de textos em duplas, como acontece nas Unidades 3 
e 9, nas páginas 93 e 262, respectivamente; ou ainda, instruindo o produtor do texto, no caso, o aluno, para que mostre 0 trabalho final ao professor, conforme indicações presentes nas Unidades 5 e 6 . Em ambas as situações, a intenção é fazer com que os autores acolham novas sugestões de outras pessoas, visando melhorar a qualidade do texto, em virtude da sugestão de novas ideias, ou de possíveis mudanças.

As propostas para a produção de textos, assim como o esperado das orientações feitas pelo professor, trazem grande diversidade de gêneros textuais, sendo estes: história em quadrinhos, resenha, contos de artimanha, cartas, fábulas, entrevistas, verbetes de enciclopédia e, estrofes de cordel.

Em cada unidade trabalhada no livro, o foco proposto baseia-se em um dos gêneros citados. Antes da proposta de produção, invariavelmente, são apresentados vários textos do gênero no decorrer da unidade, com diferentes temas, conforme pode ser visto na tabela abaixo.

Tabela 1. Especificação dos gêneros textuais no livro didático

\begin{tabular}{|l|l|l|}
\hline $\begin{array}{c}\text { Unidades do livro } \\
\text { didático }\end{array}$ & \multicolumn{1}{|c|}{ Gênero Textual Proposto } & \multicolumn{1}{|c|}{$\begin{array}{c}\text { Páginas da Proposta de } \\
\text { produção textual }\end{array}$} \\
\hline Unidade 1 & HQ- História em quadrinhos & p. 35 \\
\hline Unidade 2 & Resenha & p. 47 \\
\hline Unidade 3 & Contos de artimanha & p. 80/93 (Oficina) \\
\hline Unidade 4 & Carta & p. 125 \\
\hline Unidade 5 & Fábula & p. 156 \\
\hline Unidade 6 & Entrevista & p. 183 \\
\hline Unidade 7 & Verbete de enciclopédia & p. 214 (Oficina)* \\
\hline Unidade 8 & Cordel & p. 232/238 (Oficina)* \\
\hline Unidade 9 & Contos & p. 262/268 (Oficina) \\
\hline
\end{tabular}

*Algumas propostas são em Oficinas de Produção, por apresentar várias etapas para a construção dos textos. Fonte: Adaptado de Carpadena e Bragança (2014)

A apresentação e a interpretação desses textos ajudam a ampliar o repertório do aluno, dando subsídios e colaborando na construção da escrita no momento em que surge a proposta de produção textual. No entanto, ressalta-se que os gêneros e as características de sua estrutura são o foco nas propostas do livro, destacando-se ante qualquer outro objetivo idealizado pelas autoras.

Por essa mesma razão, o enfoque na estrutura do gênero desenvolvido e os objetivos da produção estão sempre relacionados à construção elaborada desse gênero. Semelhantemente, a temática abordada nem sempre é explícita, mesmo que seja possível percebê-la durante as leituras dos textos apresentados na unidade, ou seja, aqueles anteriores às propostas de produção de texto, ou ainda, na orientação de planejamento do mesmo. Destarte, faz-se necessária a intervenção do professor, com o objetivo de deixar claro o tema a ser abordado.

As propostas apresentam a necessidade de estruturar o texto a ser produzido em determinado gênero, sendo o tema quase sempre livre. Uma das vezes na qual foi possível identificar a temática, tratava-se de uma proposta para a produção de uma entrevista visando uma apresentação com exposição de objetos antigos, conforme orientações presentes entre as páginas 183 e 185 do livro didático. O objetivo era compartilhar lembranças dos entrevistados, a fim de mostrar como era a vida das pessoas em diferentes épocas.

Pelas observações feitas, percebe-se que há sempre presente o destinatário, ou seja, alguém a quem se escreve, ampliando a leitura dos textos para além do professor da sala. No entanto, em sua maioria, as produções são destinadas aos outros alunos, podendo ser os da turma em questão, os de outras turmas da escola, ou ainda, uma exposição para a escola inteira, realizada em algum ambiente de convívio em comum.

Nas proposituras de produção textual das Unidades 1 a 3 e 5 a 8 , verificou-se que os destinatários são os próprios alunos, podendo ser propostos para a sala em questão, para outras turmas de 4음 ano, para uma turma de 50 ano, ou mesmo para a escola em geral, com exposição no pátio. $\mathrm{Na}$ unidade 9 , os textos a serem produzidos são destinados aos familiares ou às 
pessoas da comunidade, que serão presenteados pelas crianças com essas produções.

Já a unidade 4 apresenta uma proposta que ultrapassa os portões da escola, sugerindo a escrita de cartas. As autoras propõem que o professor entre em contato com alguma escola de outro país para que os alunos possam trocar cartas, individuais, mas de envio coletivo, com a intenção de descobrir novas culturas e modos de viver de diferentes povos, em diferentes países.

Nota-se ainda que sempre há a orientação de suporte para a circulação do texto, tanto em exposição, quanto em leitura para a turma ou ainda, no jornal escolar. Do mesmo modo, há orientação quanto ao número de alunos necessários para a construção de cada produção, podendo ser individual, em duplas, em pequenos grupos ou coletiva.

Tabela 2. Organização dos alunos para a produção do texto e suporte

\begin{tabular}{|l|l|l|}
\hline $\begin{array}{c}\text { Unidades } \\
\text { do livro } \\
\text { didático }\end{array}$ & \multicolumn{1}{|c|}{ Organização } & \multicolumn{1}{|c|}{$\begin{array}{c}\text { Suportes de } \\
\text { texto }^{1}\end{array}$} \\
\hline Unidade 1 & Individual & $\begin{array}{l}\text { Exposição na } \\
\text { escola }\end{array}$ \\
\hline Unidade 2 & Coletiva & $\begin{array}{l}\text { Publicação em } \\
\text { jornal/blog }\end{array}$ \\
\hline Unidade 3 & $\begin{array}{l}\text { Duplas/ } \\
\text { Produção final- } \\
\text { coletiva }\end{array}$ & $\begin{array}{l}\text { Almanaque da } \\
\text { turma }\end{array}$ \\
\hline Unidade 4 & Individual & Envio de cartas \\
\hline Unidade 5 & Duplas & Livro da turma \\
\hline Unidade 6 & Individual & $\begin{array}{l}\text { Exposição na } \\
\text { escola }\end{array}$ \\
\hline Unidade 7 & Duplas & $\begin{array}{l}\text { Apresentação } \\
\text { oral }\end{array}$ \\
\hline Unidade 8 & Individual & Varal na escola \\
\hline Unidade 9 & Duplas & Entrega pessoal \\
\hline
\end{tabular}

Fonte: Adaptado de Carpadena e Bragança (2014)

Quanto às contribuições para a construção da textualidade, a questão temática, como relatado anteriormente, não é uma preocupação das autoras, que deixam algumas vezes a delimitação do tema a cargo do professor, como pode ser visto na proposta de

\footnotetext{
${ }^{1}$ Marcuschi (2003) afirma que a noção de suporte está relacionada com a ideia de um "portador do texto", entendido como "um locus físico ou virtual com formato específico que serve de base ou ambiente de fixação do gênero materializado como texto" (p. 11). Nesse sentido, podemos ter os suportes convencionais, criados com o propósito de suportar determinados gêneros textuais (revistas, jornais, livros, coletâneas...) e os incidentais, que podem vir a servir de suporte a um texto, mesmo não sendo criados com tal intencionalidade (para-choque de caminhão, camisetas, muros...).
}

texto presente na Unidade 8, sobre a produção de uma estrofe de cordel.

O planejamento pode utilizar a "Caixa de Ideias", para a orientação ao estudante, e, na maioria das vezes, o enfoque se dá em relação à estruturação do texto. No entanto, pode trazer outras colaborações, como no caso da Unidade 1, na página 35 , na qual se trabalha o gênero Histórias em Quadrinhos (HQ). Nesse exemplo, a "Caixa de Ideias" traz orientações para a elaboração do personagem, fornecendo detalhes em relação a características físicas e psicológicas.

Nos contos de artimanha, na Unidade 3, o planejamento é mais elaborado, já que conta com três momentos de produção e revisão da escrita, tendo em vista que o objetivo é a construção de um almanaque, o que exige maior elaboração. 0 processo de revisão, nesse caso, acontece em três momentos diferentes: o primeiro com ênfase nas características do gênero, o segundo em relação à estrutura do texto (pontuação, por exemplo) e por último, a troca entre as duplas produtivas para que sejam dadas sugestões visando o aprimoramento do texto. Estas sugestões não buscam somente identificar erros ortográficos ou inadequações gramaticais, mas, preocupam-se com as ideias desenvolvidas e verificam se são necessários ajustes no texto.

A proposta divide-se em três etapas. Primeiramente é feita a pesquisa de textos populares (quadrinhas, trava-línguas, adivinhas e provérbios), que serão incluídos no almanaque da turma (produto final); em seguida, ocorre o planejamento do conto, que deve ser feito oralmente (ambiente, situação inicial, personagens, motivação do personagem principal, no exemplo do caso de Pedro Malasartes, além da descrição de seu plano, contar como ele consegue escapar da situação criada); a última etapa é a "hora de escrever", que é a produção do texto propriamente dita. Destaca-se ainda que todo o trabalho é realizado em duplas.

No geral, a revisão se dá em forma de autoavaliação, e não há um enfoque para ajudar o aluno a se concentrar em uma característica (pontuação, coerência), pois a proposta é generalizada. A revisão tem o objetivo de verificar se os itens propostos no planejamento da produção foram executados ou não. Em alguns casos, é incluída também a verificação da gramática, como podemos ver no exemplo a seguir, referente à Unidade 9, na página 268. 


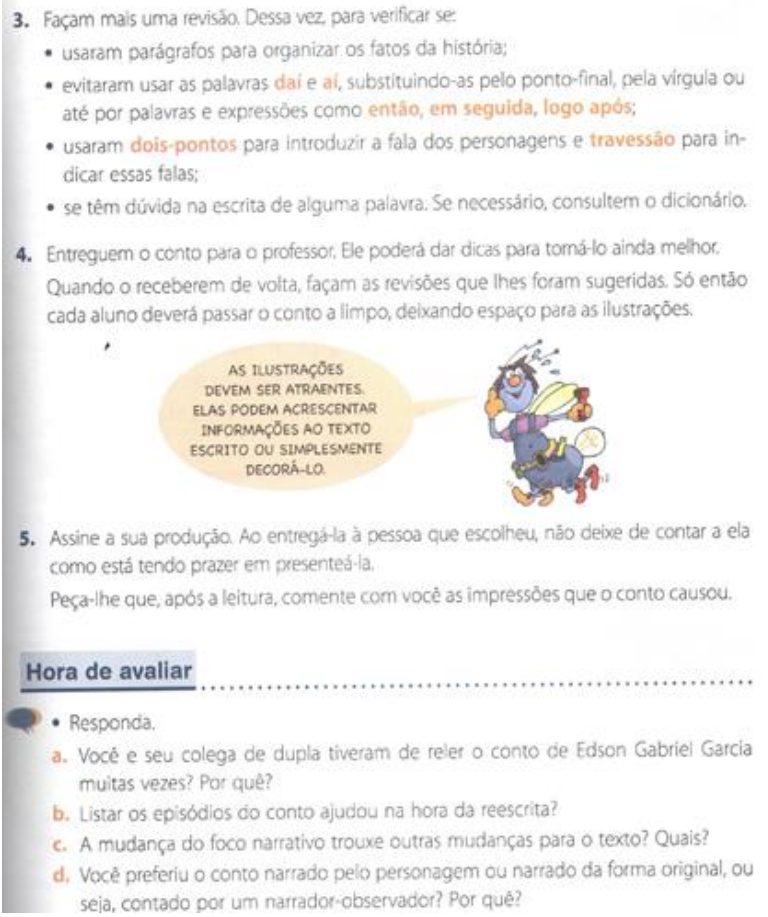

Oficina (2: parte)

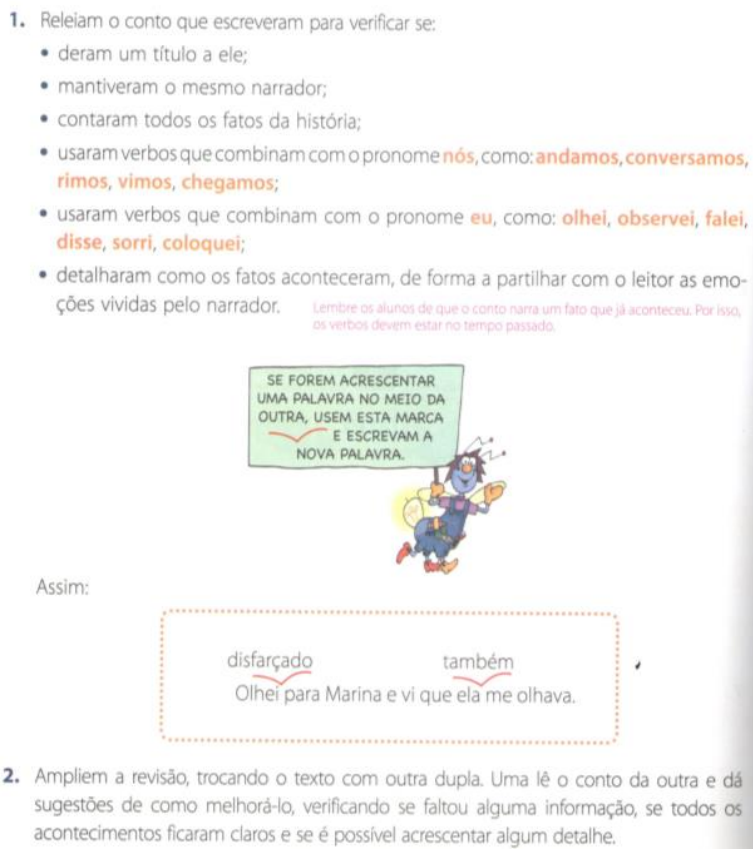

Fonte: Carpadena e Bragança (2014)

A reelaboração é parte das propostas de produção, especialmente quando essas são divididas em etapas de construção, sendo a última delas, a versão final do texto, a qual poderia ser considerada como a finalização do trabalho de revisão. Após esse processo, acontece a reescrita, parte final da produção do texto.

\section{CONSIDERAÇÕES FINAIS}

Os critérios para a avaliação das coleções de Língua Portuguesa destinadas ao Ensino Fundamental do PNLD exigem que as propostas de produção de texto explorem grande diversidade de gêneros, assim como devem considerar o uso social da escrita. Dessa forma, o trabalho precisa estar contextualizado, com orientações para a produção do aluno, abordando "os procedimentos envolvidos no planejamento, na produção, na revisão e na reescrita dos textos" (BRASIL, 2015, p.17).

Ainda sobre as propostas de produção de textos, o PNLD destaca a necessidade de que sejam criadas condições de produção, ajudando o aluno a elaborar seus textos considerando "as finalidades, os interlocutores e a situação comunicativa" (BRASIL, 2015, 28), além de adequações ao gênero e às suas características.

Na análise da coleção "Porta Aberta", edição renovada para 2016, realizada pelo PNLD, foi constatado que o conjunto de propostas de produção está de acordo com os critérios estabelecidos, no entanto, é menos consistente quanto às "orientações para o uso de registro de linguagem adequada ao gênero e à situação" (BRASIL, 2015, p.201).

Especificamente quanto ao livro desta coleção destinado ao uso no quarto ano do ensino fundamental, é possível afirmar que os critérios estabelecidos pelo PNLD, assim como as propostas do $\mathrm{PCN}$ estão sendo contempladas. $\mathrm{O}$ mesmo pode ser afirmado sob a ótica da concepção da linguagem enquanto forma de interação, tendo em vista que Carpaneda e Bragança (2014) sempre apresentam um objetivo (para quê), um destinatário (para quem) e, o suporte de circulação do texto (como), além de possibilitar a ampliação do repertório de textos dos gêneros em questão, por meio da leitura dos textos apresentados nas unidades.

No entanto, ressalta-se ainda que o objetivo principal das autoras não é a mensagem em si, mas a boa elaboração e construção da estrutura dos gêneros propostos. Neste sentido, o pensamento de Geraldi (1983 apud Colello, 2012) complementa:

[...] na escola não se produzem textos em que o sujeito diz a sua palavra, mas simula-se o uso da modalidade escrita, para que o aluno se exercite no 


\begin{abstract}
uso da escrita, preparando-se para de fato usá-la no futuro. É a velha história da preparação para a vida, encarando-se o hoje como não vida. É o exercício (GERALDI, 1983 apud COLELLO, 2012, p.65)
\end{abstract}

Na mesma perspectiva, Bakthin (2006, p. 95) afirma que "enquanto uma forma linguística for apenas um sinal e for percebida pelo receptor somente como tal, ela não terá para ele nenhum valor linguístico". Por conseguinte, apesar de serem boas as propostas de produção textual, seria necessário criar situações de uso real da linguagem em tais produções.

Não podemos negar o avanço alcançado na elaboração dos livros didáticos e faz-se necessário admitir que o livro analisado, Porta Aberta, busca contemplar todos os critérios estabelecidos pelo PNLD e pelos PCNLP, os quais preconizam uma concepção de linguagem utilizada como forma de interação. Contudo, ainda há um caminho a ser percorrido quanto ao uso efetivo e real da língua, considerando-se que, na maioria das vezes, as propostas de produção de texto ainda estão mais preocupadas em trabalhar a forma do que o conteúdo. Este pode ser considerado como a mensagem em si, aquilo que o aluno realmente quer dizer, a interação real entre os sujeitos em diferentes circunstâncias e em diferentes situações sociais, ou ainda, o uso real e efetivo da produção escrita.

\section{REFERÊNCIAS}

BAKHTIN, M. Marxismo e filosofia da Linguagem. 12.ed. São Paulo: Hucitec, 2006.

\section{BRASIL. Parâmetros Curriculares Nacionais:}

língua portuguesa: ensino fundamental. 3. ed. Brasília: MEC/SEF, 2001.

BRASIL. Ministério da Educação. Guia de livros didáticos PNLD 2016: alfabetização e letramento e língua portuguesa. Brasília, 2015. Disponível em:

<http://portal.mec.gov.br/seb/arquivos/pdf/vol1 b.pdf>. Acesso em: 25 nov. 2015.

BRITTO, L. P. L. Em terra de surdos-mudos: um estudo sobre as condições de produção de textos escolares. In: GERALDI, J. W. O texto na sala de aula. 4.ed. São Paulo: Ática, 2006.
CARPADENA, I. P. M.; BRAGANÇA, A. D. Porta aberta- língua portuguesa, 40 ano: ensino fundamental- anos iniciais. São Paulo: FTD, 2014. (Coleção Porta Aberta).

COLELLO, S. M. G. A escola que (não) ensina a escrever. 2.ed. São Paulo: Summus, 2012.

DIONÍSIO, A. P. Livros didáticos de português formam professores?. In: Congresso brasileiro de qualidade na educação - formação de professores, 2002, Brasilia. Simpósio 6: o livro didático e a formação de professores. Brasília: MEC/SEF, 2002.

GERALDI, J. W. 0 texto na sala de aula. 4.ed. São Paulo: Ática, 2006.

LUDKE, M.; ANDRE, M. E. D. A. de. Pesquisa em educação: abordagens qualitativas. São Paulo: EPU, 1986.

MARCUSCHI, L. A. A questão do suporte dos gêneros textuais. DLCV Língua, linguística e literatura, João Pessoa, v. 1, n. 1, p. 9-40, 2003. ; DIONISIO, A.P. Fala e Escrita. Belo Horizonte: Autentica, 2007.

REINALDO, M. A. G. de M.; SANT'ANA, T. F. Análise da orientação para produção de texto no livro didático como atividade de formação docente. Linguagem e Ensino, Pelotas, n. 2, v. 8, p. 97-120. jul./dez., 2005.

VOLMER, L.; RAMOS, F. B. O livro didático de Português (LDP): a variação de gêneros textuais e a formação do leitor. In: Simpósio Internacional de Estudos de Gêneros Textuais, 5., ago. 2009. Anais... Caxias do Sul: [s.n.], 2009.]

Recebido para publicação em: 26/04/2016 Revisado em: 29/04/2016

Aceito em: 02/05/2016 